\title{
Comment on Medina et al.: orthopaedic surgery patients who use recreational marijuana have less pre-operative pain
}

\author{
Harry Mai ${ }^{1}$ (D) \\ Received: 13 February 2019 / Accepted: 25 February 2019 / Published online: 5 March 2019 \\ (C) SICOT aisbl 2019
}

Dear Editor,

I read with great interest the article of Medina and colleagues in a recent issue of the journal [1]. The authors performed an observational study on 997 patients undergoing outpatient orthopaedic surgery and concluded that marijuana use was an independent factor associated with less pain intensity in the operative site. The authors should be applauded for performing a well-designed study in an important topic (e.g., acute pain) in patients undergoing orthopaedic surgery $[2,3]$. The need to improve post-operative recovery by reducing moderate-to-severe post-operative pain makes the topic very important in peri-operative medicine $[4,5]$.

Nonetheless, there are some critical points that need to be clarified by the authors to determine the validity of their findings. First, it is unclear if the authors adjusted their findings for the type of surgery because different orthopaedic procedures may cause a substantial variation on post-operative pain. Second, it is also not clear if the authors adjusted their analysis for the intra-operative or post-operative use of nerve blocks as this can also affect the primary outcome. Last, the authors should have presented opioid consumption. Marijuana use decreases opioid side effects (e.g., nausea and vomiting); therefore, it is possible that patients who used marijuana had less pain because they used more opioids [6].

I would welcome comments by the authors as this would help to further support the findings of this important study.

Harry Mai

harrytmai@gmail.com

1 Department of Anesthesiology, Rhode Island Hospital, The Warren Alpert Medical School of Brown University, 593 Eddy Street, Providence, RI 02903, USA

\section{Compliance with ethical standards}

Conflict of interest The author declares that he has no conflict of interest.

Publisher's note Springer Nature remains neutral with regard to jurisdictional claims in published maps and institutional affiliations.

\section{References}

1. Medina SH, Nadarajah V, Jauregui JJ, Smuda MP, Foster M, Meredith SJ, Packer JD, Henn RF 3rd (2018) Orthopaedic surgery patients who use recreational marijuana have less pre-operative pain. Int Orthop. https://doi.org/10.1007/s00264-018-4101-x

2. M N, Pandey RK, Sharma A et al (2018) Pectoral nerve blocks to improve analgesia after breast cancer surgery: a prospective, randomized and controlled trial. J Clin Anesth 45:12-17

3. Saito M, Tsukada S, Fujita N et al (2018) Post-operative pain control following arthroscopic rotator cuff repair: peri-articular injection versus interscalene brachial plexus block. Int Orthop. https://doi.org/10. 1007/s00264-018-4096-3

4. Pribish AM, Kalava A (2018) Are paravertebral nerve blocks an answer to pain after iliac crest bone marrow biopsy? J Clin Anesth 45:22

5. Dilmen OK, Bilgin H (2018) Pain management in spine surgery. J Clin Anesth 45:29

6. Mazzinari G, Ball L, Serpa Neto A et al (2018) The fragility of statistically significant findings in randomised controlled anaesthesiology trials: systematic review of the medical literature. Br J Anaesth 120:935-941 